\title{
Fra kliniske spørsmål til troverdige svar
}

\author{
Kunnskapsbasert praksis er basert på en kombinasjon av beste tilgjengelige forskningskunnskap, klinisk \\ ekspertise og pasientenes egne preferanser. Ved kunnskapsbasert praksis brukes redskaper for å finne \\ troverdige svar på relevante kliniske spørsmål, noe som krever ferdigheter i kunnskapshåndtering. Kunn- \\ skapshåndtering bør følges av kvalitetsforbedring for å oppnå endring i klinisk praksis.
}

\author{
Per Olav Vandvik \\ per.vandvik@gmail.com \\ Michael Bretthauer \\ Ingrid Charlotte Kongerud
}

\begin{abstract}
Bør Eva (53 år gammel), som er innlagt med akutt alvorlig pankreatitt, få ernæringssonde eller er det greit med intravenøs ernæring? En sykepleier som nettopp hadde vært på kurs, stilte dette spørsmålet til kirurgen som hadde forordnet intravenøs ernæring på visitten.
\end{abstract}

Legen skal sikre pasienten en korrekt diagnose og trygg og effektiv behandling. Kunnskapsbasert praksis (evidence-based clinical practice) er å integrere beste tilgjengelige forskningskunnskap med klinisk, erfaringsbasert ekspertise og pasientens verdier og preferanser $(1,2)$. Kunnskapsbasert praksis anses $\mathrm{i}$ økende grad som en nødvendig del av klinisk praksis, men er likevel fortsatt ikke så vanlig (3-5). Dette kan være med på å forklare gapet mellom hva leger gjør i praksis og hva de ut fra vitenskapelig dokumentasjon burde gjøre (6).

Samtidig strever klinikere med å finne gode svar på kliniske spørsmål. I en amerikansk studie stilte yngre leger på en medisinsk avdeling et nytt klinisk spørsmål for hver annen pasient (7). Kun en tredel av spørsmålene ble besvart, og oftest ved hjelp av usystematiske, tilfeldige kilder, som kolleger og lærebøker, noe som samsvarer med resultatet fra en studie med norske leger (4). Medisinske lærebøker er ikke kvalitetssikret hva gjelder innhenting, kritisk vurdering og oppdatering av kunnskapsgrunnlaget. Råd fra eldre kolleger er uvurderlig i klinisk praksis, men må også omfatte oppdatert og forskningsbasert kunnskap.

Leger må ha grunnleggende ferdigheter i å identifisere, tolke og applisere forskningsbasert kunnskap i egen praksis (8). Det er uklart hvilke krav man bør stille til faglige retningslinjer, prosedyrer eller behandlingslinjer, både hos dem som utvikler slike verktøy og hos klinikerne (9).
Kunnskapsbasert praksis kan betraktes som en verktøykasse som gjør det mulig å finne pålitelige og anvendelige svar på kliniske spørsmål. Nye metoder og verktøy gjør jakten på troverdige svar langt enklere enn tidligere. Med utgangspunkt i spørsmålet som er omtalt i den innledende vignetten (sondeernæring ved akutt pankreatitt) beskriver vi i denne kronikken en trinnvis prosess - fra erkjennelsen av et informasjonsbehov, over formulering av presise spørsmål, søk og kritisk vurdering av forskningsbasert kunnskap til integrering av kunnskapen gjennom klinisk erfaring og pasientens preferanser (fig 1). Kunnskapsbasert praksis i helsetjenesten gjelder på både individnivå og systemnivå (10).

\section{Spørsmålsformulering}

Formulering av presise spørsmål er det første steget. I spørsmålsformuleringen er det nødvendig å kjenne til at vi har ulike typer kjernespørsmål i helsetjenesten og kunne formulere presise spørsmål. Klinikere stiller som oftest spørsmål om diagnose, prognose og behandling, men kan også ha spørsmål som handler om forekomst, årsaksfaktorer, erfaringer og opplevelser.

Ulike typer kjernespørsmål krever studier med egnet design. Spørsmålet om sondeernæring ved akutt pankreatitt dreier seg om behandling og bør besvares med studier med randomisert, kontrollert design. Korrekt utført randomisering sikrer at prognostisk viktige faktorer som kan påvirke utfallet er likt fordelt mellom pasientene som får sondeernæring og pasientene som får intravenøs ernæring. Andre systematiske feil kan skyldes manglende blinding og stort pasientfrafall. Ved spørsmål knyttet til pasienters erfaringer, verdier og preferanser ville en kvalitativ studiedesign være best egnet.

Presise kliniske spørsmål tydeliggjør problemstillingen og forbereder litteratursøket. Et presist spørsmål bør inneholde informasjon om pasientgruppen vi er interessert $i$, hvilke tiltak vi vil vurdere og hvilke utfall som er aktuelle. Spørsmålene bør formuleres i såkalt PICO-format, dvs. med presis beskrivelse av pasient eller populasjon $(\mathrm{P})$, behandlingsalternativer, dvs. inter- vensjoner (I) og komparator (C) og kliniske endepunkter/utfall (outcome, O) (11). For å sikre at behandlingen gjør mer nytte enn skade, bør vi legge vekt på de endepunktene/utfallsmålene som er viktige for pasienten og huske at behandling også kan ha bivirkninger.

Et godt formulert PICO-spørsmål for denne pasientens problemstilling kan lyde som følger: Hva er effekten av sondeernæring på død, liggetid på sykehus, multiorgansvikt, operativ behandling, sepsis og smerter sammenliknet med intravenøs ernæring for pasienter med akutt alvorlig pankreatitt?

\section{Søk etter \\ forskningsbasert kunnskap}

Tradisjonelt har man i undervisningen i kunnskapsbasert praksis lagt vekt på systematiske litteratursøk og kritisk vurdering av de identifiserte studiene. Dette er tidkrevende og vanskelig å lære. God tilgang til råd og anbefalinger for diagnostikk og behandling gjennom kliniske retningslinjer er derfor nødvendig.

Figur 2 viser den såkalte kunnskapspyramiden (6S-modellen), som er utviklet for å hjelpe leger og andre helsearbeidere til raskt å finne frem til forskningsbasert kunnskap om diagnose, prognose og behandling (12). Modellen plasserer informasjonskildene $i$ et hierarki der de øverste, slik som kunnskapsbaserte oppslagsverk og retningslinjer, inneholder råd og anbefalinger basert på kvalitetsvurdert og oppsummert forskning, mens bruk av kilder lenger ned i hierarkiet, slik som systematiske oversikter og enkeltstudier, forutsetter mer kunnskap om forskning, inkludert en kritisk vurdering av resultatene.

Litteratursøk er enkelt gjennom nettbaserte tjenester som Helsebiblioteket og Pyramides $ø$. Helsebiblioteket ( $w w w$. helsebiblioteket.no) er en nettportal med over 2500 tidsskrifter, medisinske databaser, kliniske retningslinjer og oppslagsverk fritt tilgjengelig for helsepersonell (13). På førstesiden finner man Pyramidesøk, som raskt gir svar på ulike nivåer av kunnskapspyramiden gjennom ett eller to søkeord fra PICO-spørsmålet. Pyramidesøket hjelper deg også, 


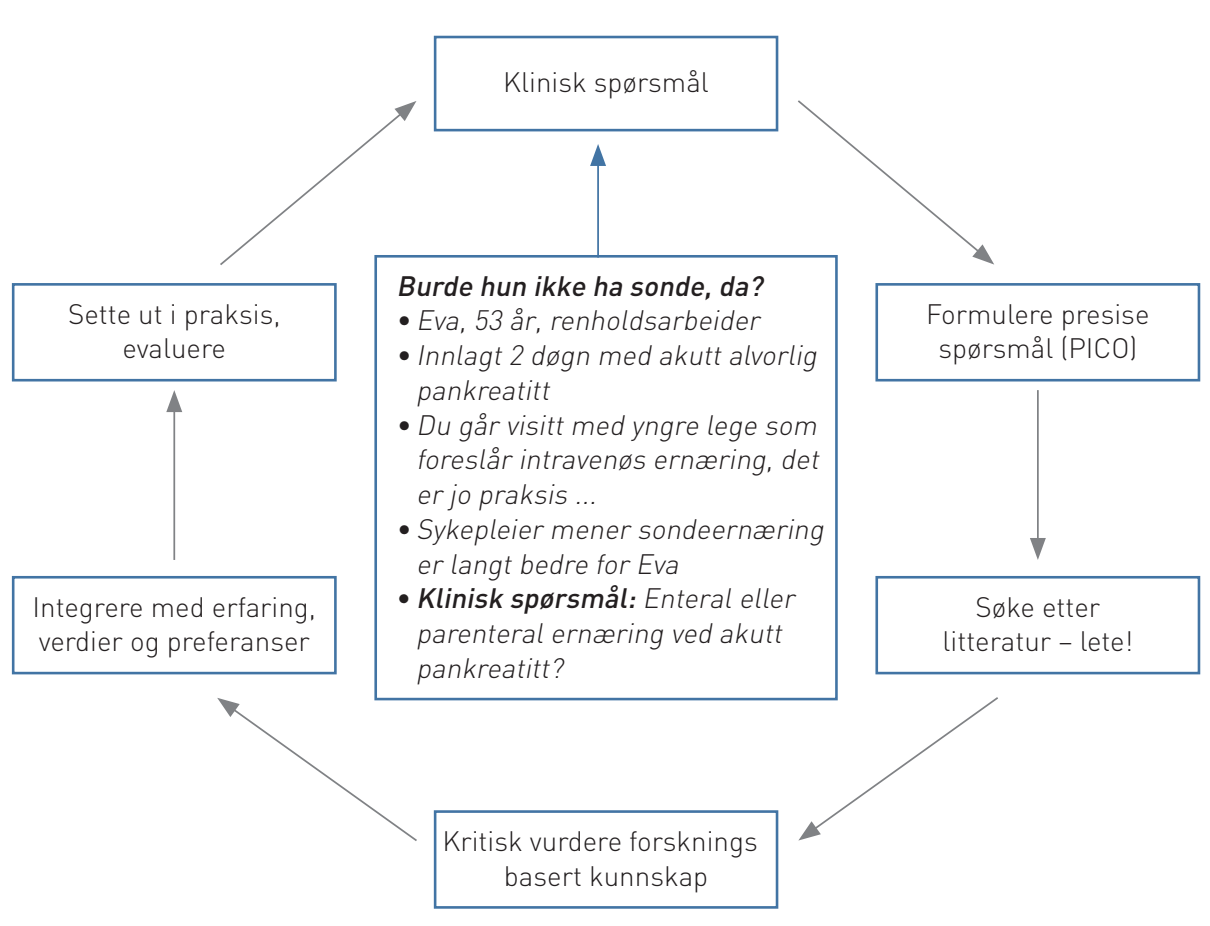

Figur 1 Eksempel på et klinisk spørsmål som utgangspunkt for en trinnvis prosess fra spørsmål til svar

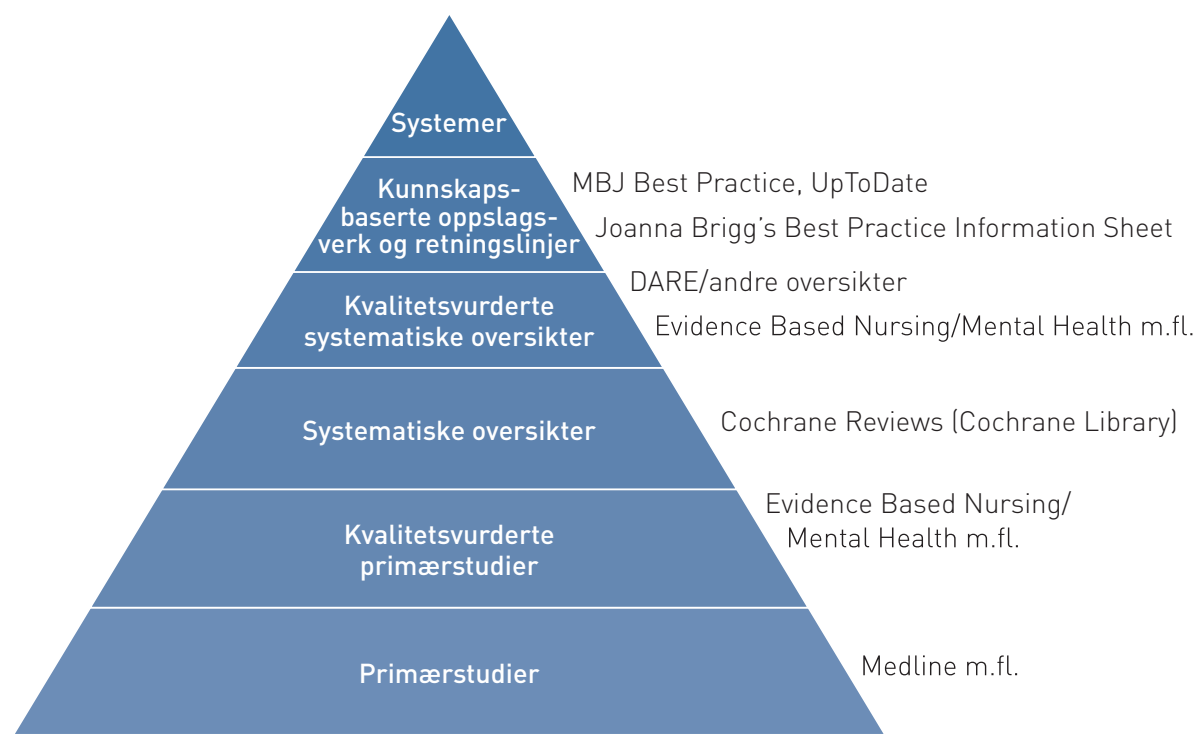

Figur 2 Kunnskapspyramiden, et hierarki av informasjonsressurser for kliniske spørsmål

gjennom søkemotoren McMaster PLUS, til å finne forhåndsvurderte systematiske oversikter og enkeltstudier som anses å være gyldige og interessante. De utvalgte studiene er enkelt tilgjengelige gjennom e-postvarsler, som fås ved registrering gjennom Helsebiblioteket. Slike e-postvarsler utgjør en god mulighet til å holde seg faglig oppdatert uten å drukne i flommen av nye studier.

E-figur 3 viser resultatene fra Pyramidesøk for spørsmålet om sondeernæring ved akutt pankreatitt. Kirurgen skrev inn søkeordet «acute pancreatitis» i søkefeltet og fant innen to minutter en relevant anbefaling i det kunnskapsbaserte oppslagsverket UpToDate. Her gis en GRADE 1B-anbefaling for ernæring med nasojejunal sonde, dvs. en sterk anbefaling (illustrert med tallet 1) med moderat kvalitet på dokumentasjonen (illustrert med bokstaven B).

Kirurgen blir overrasket. Selv om hun er litt $i$ tvil om hva som menes med GRADE 1B, oppfatter hun dette som at pasienten bør få nasojejunal sonde og ikke intravenøs ernæring. Dette er i strid med eksisterende praksis i avdelingen. Hun ønsker derfor å vite mer om grunnlaget for anbefalingen og finner med ett klikk i UpToDate et tekstavsnitt som viser til en systematisk oversikt med dokumentert positive effekter av sondeernæring på de utfallene som er viktige for pasienten (14).

\section{Kritisk vurdering}

Leger bør kunne vurdere retningslinjer og forskningsresultater kritisk før den kliniske praksisen endres. Hensikten med en kritisk vurdering er å finne ut om man kan stole på, forstå og anvende retningslinjer eller studier man vil basere sin praksis på (15). Nettkurset www.kunnskapsbasertpraksis.no gir en grundigere innføring i kritisk vurdering av faglige retningslinjer, oppsummert forskning og primærstudier med ulike typer design. Her kan man blant annet finne sjekklister som redskap for å stille de riktige spørsmålene om f.eks. studienes pålitelighet.

Ett alternativ til tradisjonell kritisk vurdering med sjekklister er GRADE-systemet (Grading of Recommendations Assessment, Development and Evaluation (e-ramme 1) (16). Dette er en metode for systematisk og transparent vurdering av kvalitet ved forskningsbasert kunnskap og for utvikling av faglige retningslinjer. GRADE-systemet er utviklet av organisasjoner som deltar i utvikling av retningslinjer og kunnskapsoppsummering, bl.a. Cochrane-samarbeidet. Helsedirektoratet anbefaler bruk av GRADE ved utarbeiding av faglige retningslinjer (17).

Kunnskapsbaserte oppslagsverk og retningslinjer skal gi balanserte anbefalinger ved å integrere forskningsbasert kunnskap med klinisk ekspertise, pasientpreferanser og andre kontekstuelle faktorer, bl.a. hvilke ressurser som er tilgjengelige (17). Nye standarder og kriterier for retningslinjer fordrer bl.a. en systematisk gjennomgang av dokumentasjon og en balansert vurdering av fordeler og ulemper ved forskjellige behandlingsalternativer $(18,19)$. Utvikling av retningslinjer er en krevende oppgave. Dette illustreres av en studie av et tilfeldig utvalg internasjonale retningslinjer, der under halvparten oppfylte etablerte kriterier for troverdighet (9). Situasjonen er ikke bedre for norske retningslinjer og fagprosedyrer.

Godt utførte systematiske oversikter med oppsummert forskning gjennom metaanalyser utgjør det beste kunnskapsgrunnlaget for anbefalingene man finner i retningslinjer og bør benyttes som grunnlag for kliniske beslutninger i fravær av gode retningslinjer. Kriterier for kritisk vurdering av retningslinjer inkluderer klart formulerte spørsmål, eksplisitte inklusjonskriterier, systematiske litteratursøk, kritisk vurdering 
av enkeltstudier og sammenfatning av resultatene gjennom adekvate metoder, slik som metaanalyser. Effektestimatene fra metaanalyser vises som en firkantet diamant og gir det relative effektestimatet for behandling (e-fig 4).

Enkeltstudier er plassert nederst i kunnskapspyramiden fordi de ikke er sammenholdt med øvrige studier og fordi de kan være beheftet med feilkilder eller andre forhold som innebærer at de ikke er anvendbare i klinisk praksis (20). Likevel kan enkeltstudier av og til - etter at det er gjort en systematisk gjennomgang av dokumentasjon og en kritisk vurdering være det beste kunnskapsgrunnlaget for klinisk praksis (21).

UpToDates sterke anbefaling for sondeernæring med nasojejunal sonde for vår pasient Eva med pankreatitt er basert på en godt utført systematisk Cochrane-oversikt og metaanalyse. At Cochrane-oversikten utgjør det beste kunnskapsgrunnlaget for spørsmålet om ernæring ved akutt pankreatitt, bekreftes ved at den gjenfinnes høyt oppe i kunnskapspyramiden, på nivået under kunnskapsbaserte oppslagsverk og retningslinjer (e-fig 3).

E-figur 4 viser et balansediagram lforest plot) fra Cochrane-metaanalysen for utfallet mortalitet. Sondeernæring ved akutt pankreatitt gir en relativ risikoreduksjon på $50 \%$ og en absolutt risikoreduksjon på $8 \%$ lantall som må behandles/number needed to treat, NNT = 12) sammenliknet med intravenøs ernæring. Kirurgen tolker dette som en imponerende effekt både når det gjelder relativ og absolutt effekt av sondeernæring.

Ofte er de absolutte effektene av en behandling mindre imponerende enn de relative effektene. Et godt eksempel er mammografiscreening, der den relative risikoen for død av brystkreft er redusert med $10 \%$ etter innføring av mammografiscreening. Den tilsvarende absolutte risikoreduksjonen er imidlertid under $0,5 \%$ (22). Like viktig som å kunne tolke relative og absolutte effekter er det å kunne balansere fordeler og ulemper ved å identifisere effekter på andre utfall som er viktige for pasienten.

Kirurgen bestemmer seg for å lese Cochrane-oversikten og finner raskt resultatene av metaanalysen oppsummert i en «GRADE Summary of findings table». E-figur 5 viser utdrag fra denne tabellen, der forfatterne gjennom bruk av GRADE-systemet oppsummerer relative og absolutte effekter av behandling samt kvalitet på dokumentasjonen på tvers av de pasientviktige utfallene.

\section{Anvendelse og evaluering av ny kunnskap i praksis}

Det siste steget i kunnskapsbasert praksis er å sette ny kunnskap ut i livet og evaluere praksisendringen. Dette krever iverksetting av systematiske tiltak for kvalitetsforbedring (23).

\section{Kirurgen som oppdaget at sondeernæring} var bedre enn intravenøs ernæring ved akutt pankreatitt, finner støtte i en sterk anbefaling $i$ UpToDate og mener det er behov for å endre praksis, gitt de dramatiske gevinstene. Kollegene er enige, men vet imidlertid ikke helt hvordan de nå skal gå frem.

Systematisk kvalitetsforbedring er i liten grad integrert i klinisk arbeid og i legers spesialistutdanning. Det finnes imidlertid gode undervisningsmetoder, verktøy og systemer (23). Medisinstudenter ved Universitetet i Oslo lærer om kunnskapsbasert praksis og systematisk kvalitetsforbedring gjennom faget kunnskapshåndtering, ledelse og kvalitetsforbedring, omtalt som KLoK-faget (24). Helse- og omsorgsdepartementet og Helsedirektoratet har foreslått å innføre obligatorisk utdanning i kunnskapsbasert praksis og kvalitetsforbedring også i spesialistutdanningen (23).

En gruppe legestudenter i Oslo har vist hvordan et lokalsykehus kan ta i bruk sondeernæring hos pasienter med akutt pankreatitt (25). Studentene gjennomførte en oppgave under studiet i kontakt med kirurgisk avdeling, som nå har gode forutsetninger til å gjennomføre tiltaket i praksis.

\section{Trening i kunnskapshåndtering}

Det er nødvendig med mye øvelse for å få tilstrekkelige ferdigheter i kunnskapshåndtering (8). Undervisning på området inngår nå i medisinstudiet i Oslo (24), bl.a. gjennom klinisk integrert læring med arbeidsfiler (25). I en artikkel i dette nummer av Tidsskriftet beskriver vi hvordan medisinstudentene i Oslo lærer kunnskapshåndtering gjennom klinisk integrert læring med arbeidsfiler (26). Undervisning i kunnskapshåndtering er også på vei inn i studiene i Tromsø og Trondheim og er foreslått som en sentral undervisningsmodul i spesialistutdanningen.

Det er også utviklet kurs i kunnskapshåndtering for sykehusleger og en nordisk workshop for alle yrkesgrupper. Inntil videre kan man benytte nettkurset www.kunnskapsbasertpraksis.no og arbeidsfiler for å oppøve praktiske ferdigheter i kunnskapshåndtering. Slik kan vi sikre at leger gjør mer nytte enn skade gjennom god diagnostikk og trygg og effektiv behandling.

e-fig 3, e-fig 4, e-fig 5 og e-ramme 1 finnes

i Tidsskriftets elektroniske utgaver.

\section{Per Olav Vandvik (f. 1968)}

underviser i KLoK-faget ved medisinstudiet i Oslo. Han er førsteamanuensis ved Avdeling for helseledelse og helseøkonomi, Universitetet i Oslo, forsker ved Nasjonalt kunnskapssenter for helsetjenesten og konstituert overlege ved Medisinsk avdeling, Sykehuset Innlandet, Divisjon Gjøvik.

Forfatter har fylt ut ICMJE-skjemaet og oppgir ingen interessekonflikter.

\section{Michael Bretthauer (f. 1969)}

er undervisningsleder i KLoK-faget ved Universitetet i Oslo, professor ved Avdeling for helseledelse og helseøkonomi, Universitetet i Oslo, overlege ved Seksjon for fordøyelsessykdommer, Avdeling for transplantasjonsmedisin, Oslo universitetssykehus, og forskningsveileder ved Sørlandet sykehus.

Forfatter har fylt ut ICMJE-skjemaet og oppgir følgende interessekonflikter: Han er medlem av vitenskapelig rådgivningsgruppe for Exact Sciences og har mottatt konsultasjonshonorar fra Norchip/advokatfirmaet Hjort.

\section{Charlotte Kongerud (f. 1988)}

er medisinstudent ved Universitetet i Oslo og har arbeidet $\mathrm{i}$ to år som deltids forskningsassistent ved Institutt for helse og samfunn, Universitetet i Oslo, med et prosjekt i kunnskapsbasert praksis

Forfatter har fylt ut ICMJE-skjemaet og oppgir ingen interessekonflikter.

\section{Litteratur}

1. Sackett DL, Rosenberg WM, Gray JA et al. Evidence based medicine: what it is and what it isn't. BMJ 1996; 312: $71-2$.

2. Wyller TB. Hvilken kunnskap om kunnskapen? Tidsskr Nor Legeforen 2011; 131: 1741.

3. Guyatt G, Cook D, Haynes B. Evidence based medicine has come a long way. BMJ 2004; 329: 990-1.

4. Ulvenes LV, Aasland O, Nylenna M et al. Norwegian physicians' knowledge of and opinions about evidence-based medicine: cross-sectional study. PLoS ONE 2009; 4: e7828.

5. Vandvik PO, Eiring O. Kunnskapsbasert praksis for norske leger? Tidsskr Nor Legeforen 2011; 131: 1755-6.

6. Grol R, Grimshaw J. From best evidence to best practice: effective implementation of change in patients' care. Lancet 2003; 362: 1225-30.

7. Green ML, Ciampi MA, Ellis PJ. Residents' medical information needs in clinic: are they being met? Am J Med 2000; 109: 218-23.

8. Glasziou P, Burls A, Gilbert R. Evidence based medicine and the medical curriculum. BMJ 2008; 337: a1253.

9. Kung J, Miller RR, Mackowiak PA. Failure of clinical practice guidelines to meet institute of medicine standards: Two more decades of little, if any, progress. Arch Intern Med 2012; 172: 1628-33.

10. Vandvik PO, Eiring O. Foretaksprosjektet: mot kunnskapsbasert praksis i spesialisthelsetjenes ten. Oslo: Nasjonalt kunnskapssenter for helsetjenesten, 2011

11. Guyatt GH, Oxman AD, Kunz R et al. GRADE guidelines: 2. Framing the question and deciding on important outcomes. $J$ Clin Epidemiol 2011; 64 : $395-400$ 
12. DiCenso A, Bayley L, Haynes RB. Accessing preappraised evidence: fine-tuning the $5 \mathrm{~S}$ model into a 6S model. Evid Based Nurs 2009; 12: 99-101.

13. Nylenna M, Eiring 0, Strand $G$ et al. Wiring a nation: putting knowledge into action. Lancet 2010 375: 1048-51.

14. Al-Omran M, Albalawi ZH, Tashkandi MF et al. Enteral versus parenteral nutrition for acute pancreatitis. Cochrane Database Syst Rev 2010; 1: CD002837.

15. Guyatt GH, Haynes RB, Jaeschke RZ et al. Users Guides to the Medical Literature: XXV. Evidencebased medicine: principles for applying the Users Guides to patient care. JAMA 2000; 284: 1290-6.

16. Guyatt GH, Oxman AD, Kunz R et al. What is «quality of evidence» and why is it important to clinicians? BMJ 2008; 336: 995-8.

17. Veileder for utvikling av kunnskapsbaserte retningslinjer. Oslo: Helsedirektoratet, 2012

18. Laine C, Taichman DB, Mulrow C. Trustworthy clinical guidelines. Ann Intern Med 2011; 154: 774-5.

19. Qaseem A, Forland F, Macbeth F et al. Guidelines International Network: toward international standards for clinical practice guidelines. Ann Intern Med 2012: 156: 525-31.

20. loannidis JP. Why most published research findings are false. PLoS Med 2005; 2: e124.

21. Vandvik PO, Lincoff AM, Gore JM et al. Primary and secondary prevention of cardiovascular disease: antithrombotic therapy and prevention of thrombosis. 9. utg. American College of Chest Physicians Evidence-Based Clinical Practice Guidelines. Chest 2012; 141 (suppl): e637S-68S.

22. Hem E. Effekter av og ulemper ved mammografiscreening. Tidsskr Nor Legeforen 2013; 133: 508.

23. Meld.St. nr.10 (2012-2013). God kvalitet - trygge tjenester. Kvalitet og pasientsikkerhet i helseog omsorgstjenesten.

24. Frich JC, Gran SF, Vandvik PO et al. Kunnskapshåndtering, ledelse og kvalitetsforbedring i legestudiet. Tidsskr Nor Legeforen 2012; 132: 1768-71.

25. Haslestad SF, Wibetoe G. Høyset HM et al. Implementering av evidensbasert ernæringsregime ved akutt alvorlig pankreatitt. Prosjektoppgave. Oslo: Institutt for helse og samfunn, Universitetet i Oslo, 2012

26. Kongerud IC, Vandvik PO. Arbeidsfiler som læringsverktøy i kunnskapshåndtering. Tidsskr Nor Legeforen 2013; 133: 1587-90.

Mottatt 13.5. 2013, første revisjon innsendt 5.6. 2013, godkjent 20.6. 2011. Medisinsk redaktør Petter Gjersvik. 